\title{
Geopolitical Risks and Movements in Islamic Bond and Equity Markets: A Note
}

\author{
Elie Bouri ${ }^{\mathrm{a}, *}$, Riza Demirer ${ }^{\mathrm{b}}$, Rangan Gupta ${ }^{\mathrm{c}}$ and Hardik A. Marfatia ${ }^{\mathrm{d}}$
}

aUSEK Business School, Holy Spirit University of Kaslik, Jounieh, Lebanon;

bDepartment of Economics and Finance, Southern Illinois University Edwardsville, Edwardsville, IL, USA;

'Department of Economics, University of Pretoria, Pretoria, South Africa;

dDepartment of Economics, Northeastern Illinois University, Chicago, IL, USA

*Contact: eliebouri@usek.edu.lb

\begin{abstract}
This study applies a non-parametric causality-in-quantiles test to examine the causal effect of geopolitical risks on return and volatility dynamics of Islamic equity and bond markets. Geopolitical risks are generally found to impact Islamic equity market volatility measures, rather than returns. However, Geopolitical risks tend to predict both returns and volatility measures of Islamic bonds. Interestingly, causality, when it exists for returns and/or volatility of Islamic equities and bonds, is found to hold over entire conditional distributions of returns and volatilities, barring the extreme ends of the same.

Keywords: Geopolitical Risks, Islamic Stock and Bond Markets, Returns and Volatility, Quantile Causality.

JEL Codes: C22, G15.
\end{abstract}

\# We would like to thank two anonymous referee for many helpful comments. However, any remaining errors are solely ours. 


\section{Introduction}

Geopolitical risks (GPRs) are often cited by central bankers, financial press and corporate managers as one of the determinants of investment decisions, and hence, are believed to affect business cycles and financial markets globally (Caldara and Iacoviello, 2016). One can argue that the effect of geopolitical risks on investment decisions and thus the performance of underlying financial assets would be particularly severe in countries where geopolitical tensions are relatively stronger and more persistent. There is little doubt that the Middle East region includes some of the most troubled countries in the world plagued by persistent geopolitical tensions such as political instability, military conflicts, and terrorist threats. Interestingly, however, this region along with some Southeast Asian countries host firms that account for the largest share of Islamic financial assets that have been documented to show better performance and more stability during periods of market stress (e.g. Hasan and Dridi, 2010; Askari, 2012; Beck et al., 2013, among others). Several recent studies including Abu-Alkheil et al. (2017) and Hikri et al. (2017) point to a decoupling of Islamic indices from their conventional counterparts during turbulent periods, suggesting that these securities can even serve as a safe haven for investors during financial crises. These observations present an interesting puzzle; however, i.e. how is it possible that Islamic securities that are issued by firms from some of the most troubled spots in the world (in terms of geopolitical risks) can serve as a safe haven during turbulent times as the literature suggests? This paper aims to provide an insight to this puzzle by examining the impact of geopolitical risks on Islamic equity and bond markets via a novel nonparametric causality-inquantiles test.

Indeed, Islamic financial industry has experienced extraordinary growth over the last decade as the industry reached almost $\$ 1.86$ trillion by the end of 2014 (Azmat et al., 2017), while the total value of Islamic finance assets under management is predicted to reach $\$ 6.5$ trillion by 2020 (Balcilar et al., 2015). Islamic securities are distinctive assets that englobe only financial assets that comply with Islamic law (Shari'ah). Azmat et al. (2017) argue that the difference between 
conventional and Islamic financial instruments can be due to four considerations: (i) firm specific variables such asset backing and the risk sharing features specific to an issue; (ii) Islamic structural differences that involve religious auditing and compliance rules; (iii) industry type that drive the profitability of firms due to the difference in operating margins across industries; and (iv) external events such as the 2008 global financial crisis. Some argue that ethical investing rules rooted from the compliance with the Sharia'h principles, along with requirements on risk sharing and asset backing, limit the risk in Islamic securities, particularly during stress periods (e.g. Ho et al., 2014; Dewandaru et al., 2017). This is in contrast to the conventional financial markets where there is no natural protection from liquidity and leverage risks.

On the other hand, regarding geopolitical risks, the literature shows that conventional financial markets have not been immune to GPRs with negative effects observed at both the aggregate and sector level (e.g. Chen \& Siems 2004, Charles \& Darné 2006, Kollias et al. 2011). While the literature on Islamic finance suggests that Islamic securities are more resistant to market risks compared to their conventional counterparties, the fact that they originate largely from countries in the Middle East and Southeast Asia where geopolitical risks are severe, could nullify any risk reduction benefits these assets might offer for conventional investors. ${ }^{1}$ In fact, one can argue that Islamic securities may exhibit a particular response to geopolitical risks than conventional assets as Guyot (2011) notes, which would indicate that the excess returns offered by these assets are merely a premium investors require for the geopolitical risks inherent in these assets. All of these discussions warrant a direct analysis of causal relationships between GPRs and risk and return experienced in this growing segment of financial assets. To that end, the nonparametric causality-in-quantile approach of Balcilar (2016a) provides a valuable tool that allows us to uncover the causality from geopolitical risks to the return and volatility of Islamic securities during normal and extreme market states characterized by lower, middle, and upper quantiles.

\footnotetext{
${ }^{1}$ More recently, on June 5, 2017, the Qatari stock market index tumbled more than 7 percent following intensified political tensions between Qatar and its Gulfneighbours (Saudi Arabia, UAE, and Bahrain).
} 
From a practical perspective, the results are likely to provide additional insights into the optimal international portfolio allocation decisions and whether or not the excess returns offered by these assets are in part a compensation for the geopolitical risks these assets are more severely exposed to. While Islamic securities provide unique diversification gains due to the presence of Islamic law principles, any event that leads to a sudden spike in the geopolitical risks is likely to impact the venue-country markets (in the words of Bandyopadhyay et al. 2014) as well as its global counterparts. This reduces the extent of diversification gains in managing international portfolio. Finally, an understating of the causal effects on risk and return in the Islamic stock and bond markets based on GPRs can enhance our understating of the extent to which Shariacompliance can mitigate the negative effect of GPRs, if any.

Our findings show that geopolitical risks impact volatility in Islamic equities, rather than returns, in line with the findings for other emerging, conventional stock markets. However, we find that geopolitical risks can predict both returns and volatility measures for Islamic bonds, while causality is found to hold over the entire conditional distributions of returns and/or volatilities, barring the extreme ends of the same. We argue that the robust results observed for Islamic bonds is due to the fact that the issuance of Islamic bonds is driven by sovereigns and governments, particularly in the Gulf Arab countries, reflecting geopolitical effects on the sovereign's political situation and finances, and possibly relating GPR to the credit risk of the issuers of Islamic bonds. To that end, it can be argued that the excess returns observed on Islamic bonds are largely a compensation for the inherent risks driven by geopolitical risk exposures of issuing firms and sovereigns. Overall, our results imply that Islamic financial instruments are affected by geopolitical risks just as the conventional markets. This noteworthy finding enriches the common view that Islamic financial assets are subject to less risk than conventional ones, and thus implies the need for investors and policy-makers to set plans for contingencies to address some of the implications of geopolitical uncertainty. 
The rest of the paper is organized as follows: Section 2 reviews the related literature. Section 3 presents the methodology, while Section 4 discusses the data and the results. Finally, Section 5 concludes.

\section{Related studies}

Our paper is related to two strands of the literature. The first strand focuses on the particularity of Islamic assets (stock and bond markets), their relation with conventional assets, and possible diversification gains these assets might offer as well as their price formation. Herwaniy and Febrian (2013) and Shaista and Rizvi (2013) argue the compliance of Islamic equities with Sharia'h principles make Islamic equities less risky and more resistant to financial failure than conventional equities. Accordingly, several studies has raised the issue of whether Islamic securities can be regarded as an alternative to conventional assets. Using a dynamic three-regime and three-factor risk spillover model, Balcilar et al. (2015) show that adding Islamic equity sectors to portfolios enhances risk adjusted returns. Importantly, the authors argue that Islamic consumer services, oil and gas and information technology exhibit negative risk exposure, especially during crash periods, implying potential safe-haven benefits. Using a Markov regimeswitching GARCH model, Balcilar et al. (2016c) study the international diversification benefits of Islamic bonds for equity portfolios. They find weak correlation between Islamic bonds and global stock markets, particularly during market crisis periods, suggesting valuable diversification benefits. In more recent studies, Abu-Alkheil et al. (2017) and Hikri et al. (2017) show evidence of decoupling of Islamic indices from their conventional counterparts during turbulent periods, suggesting that these securities can even serve as a safe haven for investors during financial crises.

Extending the literature to return predictability, using 14 global economic and financial variables, Gupta et al. (2014) find weak evidence of predictability based on US 3-month Treasury rates, inflation, oil and US equity returns, and argue that Islamic equity returns are best predicted based 
on their lagged returns. Focusing on causal relationships, Ajmi et al. (2014) show evidence of significant bi-directional linear and non-linear Granger causalities between Islamic and conventional equity markets and interest rates, whi;e Bahloul et al. (2017) argue that conventional stock indices returns and money supply have a significant effect on Islamic stock indices independent of the state of the volatility regimes. Naifar and Hammoudeh (2016) show that global financial distress and various uncertainty factors (such as financial and commodity market and economic policy uncertainty indices) have a significant impact and causality effect on the Islamic bond returns.

Separately, Naifar et al. (2017) focus on the impact of regional and global uncertainty factors on conventional bond and Islamic bond returns dynamics. Using quantile regression, the authors show that the responsiveness of Islamic bonds to those factors differs from that of conventional bonds. Reboredo and Naifer (2016) apply a quantile regression to examine the relationship between Islamic bond prices and financial and policy uncertainty conditions from 2010-2014. They reveal that US bond prices have a negative effect on Islamic bond prices, whereas financial uncertainty has a negative effect during normal periods only. Furthermore, Islamic bond prices are found to be independent of economic policy uncertainty and stock market returns. Recently, Trabelsi and Naifer (2017) highlight the weak effect of systemic risk on Islamic stock indices, pointing toward the diversification benefits of adding Islamic equities.

The second stand of research that our paper relates to has focused on the economic impacts of wars, armed conflicts, and terrorist attacks on the return and volatility of financial markets. Kollias et al. (2010) use event study methodology and GARCH family models to examine the effects of the Israeli military offensive of 2008-2009 on the Gaza Strip on the returns and volatility of Israeli equities and government bonds. The authors find significant impact on both markets, with evidence of a switching behavior between stock and bond markets according to the outcome of the military offensive. Using a similar method, Kollias et al. (2011a) show that the bomb attacks of 11th March 2004 in Madrid and 7th July 2005 in London have a transitory 
impact on the return and volatility of the domestic stock market in Spain and the UK. Furthermore, Kollias et al. (2011b) indicate that the reaction of financial market returns and volatility is affected by market size and maturity as well as specific attributes of terrorist attacks. In a follow up study, Kollias et al. (2013a) argue that both equity and bond markets are shaped by terrorist incidents, which trigger a flight-to-safety effect primarily in France and Germany and to a lesser extent in the UK and Spain. Similarly, using a multivariate GARCH model, Kollias et al. (2013b) reveal that the covariance between oil returns and the returns of US and leading European equities are also affected by war.

In other studies that specifically focus on emerging stock markets, Aslam and Kang (2015) find that terrorist attacks have a short-lived negative effect on Pakistani stock returns, arguing that the intensity of effect depends on the locations and types of attack. Similarly, examining the impact of both crisis and war periods on the return of twelve equity markets in the Middle East and North Africa, Bouri (2014) shows that, although war and financial crisis shocks caused harmful consequences in most of the studied markets, the benefits of regional diversification can be still achieved. Finally, Balcilar et al. (forthcoming) show that the effect of geopolitical risks is heterogeneous across the BRICS stock markets and is more significant on volatility measures than on returns. In a paper that is similar to the methodology employed in our study, Balcilar et al. (2016b) examine the effects of terror attacks on stock-market returns and volatility in G7 countries. While the authors show that terror attacks have significant effects on returns in most cases for some upper and lower quantiles, the effect on volatility is significant only for the cases of Japan and the UK in some moderate upper quantiles.

Overall, the findings presented in the literature highlight the significant effects of security shocks (wars, armed conflicts, and terrorism) on returns and volatility in conventional financial markets, although the effects are not homogeneous across the bond and stock markets and across countries. To the best of our knowledge, the effects of geopolitical risks on Islamic equity and bond markets remain unexplored, although geopolitical risk has been become a "sustenance" for 
countries where most of Islamic securities are originated and concentrated. The closest study to ours is Guyot (2011) who highlights the sensitivity of Islamic indices to geopolitical events. However, this study overlooks the effects on both the returns and volatility of Islamic equity and bond markets, without distinguishing between normal and extreme market states.

\section{Methodology}

This section provides a brief description of the quantile based methodology that we use to detect nonlinear causality via a hybrid approach developed by Balcilar et al. (2016a). Let $y_{t}$ denote stock or bond returns and $x_{t}$ denote the predictor variable, in our case GPR (as described in detail in the next Section).

Formally, let $\quad Y_{t-1} \equiv\left(y_{t-1}, \ldots, y_{t-p}\right), \quad X_{t-1} \equiv\left(x_{t-1}, \ldots, x_{t-p}\right), \quad Z_{t}=\left(X_{t}, Y_{t}\right) \quad$ and $F_{y_{t} \mid Z_{t-1}}\left(y_{t}, Z_{t-1}\right)$ and $F_{y_{t} \mid Y_{t-1}}\left(y_{t}, Y_{t-1}\right)$ denote the conditional distribution functions of $y_{t}$ given $Z_{t-1}$ and $Y_{t-1}$, respectively. If we denote $Q_{\theta}\left(Z_{t-1}\right) \equiv Q_{\theta}\left(y_{t} \mid Z_{t-1}\right)$ and $Q_{\theta}\left(Y_{t-1}\right) \equiv Q_{\theta}\left(y_{t} \mid Y_{t-1}\right)$, we have $F_{y_{t} \mid Z_{t-1}}\left\{Q_{\theta}\left(Z_{t-1}\right) \mid Z_{t-1}\right\}=\theta$ with probability one. Consequently, the (non)causality in the $\theta$-th quantile hypotheses to be tested can be specified as:

$$
\begin{gathered}
H_{0}: \quad P\left\{F_{y_{t} \mid Z_{t-1}}\left\{Q_{\theta}\left(Y_{t-1}\right) \mid Z_{t-1}\right\}=\theta\right\}=1, \\
H_{1}: \quad P\left\{F_{y_{t} \mid Z_{t-1}}\left\{Q_{\theta}\left(Y_{t-1}\right) \mid Z_{t-1}\right\}=\theta\right\}<1 .
\end{gathered}
$$

Jeong et al. (2012) employ the distance measure $J=\left\{\varepsilon_{t} E\left(\varepsilon_{t} \mid Z_{t-1}\right) f_{z}\left(Z_{t-1}\right)\right\}$, where $\varepsilon_{t}$ is the regression error term and $f_{z}\left(Z_{t-1}\right)$ is the marginal density function of $Z_{t-1}$. The regression error $\varepsilon_{t}$ emerges based on the null hypothesis in (1), which can only be true if and only if $E\left[1\left\{y_{t} \leq Q_{\theta}\left(Y_{t-1}\right) \mid Z_{t-1}\right\}\right]=\theta$ or, equivalently, $1\left\{y_{t} \leq Q_{\theta}\left(Y_{t-1}\right)\right\}=\theta+\varepsilon_{t}$, where $\mathbf{1}\{\Varangle \quad$ is an indicator function. Jeong et al. (2012) show that the feasible kernel-based sample analogue of $\boldsymbol{J}$ has the following form:

$$
\hat{J}_{T}=\frac{1}{T(T-1) h^{2 p}} \sum_{t=p+1}^{T} \sum_{s=p+1, s \neq t}^{T} K\left(\frac{Z_{t-1}-Z_{s-1}}{h}\right) \hat{\varepsilon}_{t} \hat{\varepsilon}_{s} .
$$


where $K(\cdot)$ is the kernel function with bandwidth $h, T$ is the sample size, $p$ is the lag order, and $\hat{\varepsilon}_{t}$ is the estimate of the unknown regression error, which is estimated as follows:

$$
\hat{\varepsilon}_{t}=1\left\{y_{t} \leq Q_{\theta}\left(Y_{t-1}\right)\right\}-\theta \text {. }
$$

$\hat{Q}_{\theta}\left(Y_{t-1}\right)$ is an estimate of the $\theta^{\text {th }}$ conditional quantile of $y_{t}$ given $Y_{t-1}$, and we estimate $\hat{Q}_{\theta}\left(Y_{t-1}\right)$ using the nonparametric kernel method as

$$
\hat{Q}_{\theta}\left(Y_{t-1}\right)=\hat{F}_{y_{t} \mid Y_{t-1}}^{-1}\left(\theta \mid Y_{t-1}\right),
$$

where $\hat{F}_{y_{t} \mid Y_{t-1}}\left(y_{t} \mid Y_{t-1}\right)$ is the Nadarya-Watson kernel estimator given by

$$
\hat{F}_{y_{t} \mid Y_{t-1}}\left(y_{t} \mid Y_{t-1}\right)=\frac{\sum_{s=p+1, s \neq t}^{T} L\left(\left(Y_{t-1}-Y_{s-1}\right) / h\right) 1\left(y_{s} \leq y_{t}\right)}{\sum_{s=p+1, s \neq t}^{T} L\left(\left(Y_{t-1}-Y_{s-1}\right) / h\right)},
$$

with $L(\cdot)$ denoting the kernel function and $h$ the bandwidth.

In an extension of Jeong et al. (2012)'s framework, Balcilar et al., (2016a) also develop a test for the second moment. In particular, we can now test the causality running from GPR to volatility of stock or bond returns. Adopting the approach in Nishiyama et al. (2011), higher order quantile causality can be specified as:

$$
\begin{array}{ll}
H_{0}: P\left\{F_{y_{t}^{k} \mid Z_{t-1}}\left\{Q_{\theta}\left(Y_{t-1}\right) \mid Z_{t-1}\right\}=\theta\right\}=1 & \text { for } k=1,2, \ldots, K \\
H_{1}: \quad P\left\{F_{y_{t}^{k} \mid Z_{t-1}}\left\{Q_{\theta}\left(Y_{t-1}\right) \mid Z_{t-1}\right\}=\theta\right\}<1 & \text { for } k=1,2, \ldots, K
\end{array}
$$

Integrating the entire framework, we define that $x_{t}$ Granger causes $y_{t}$ in quantile $\theta$ up to the $k^{\text {th }}$ moment using Eq. (7) to construct the test statistic of Eq. (3) for each $k$. The causality-invariance test is then calculated by replacing $y_{t}$ in Eqs. (3) and (4) with $y_{t}^{2}$. However, it can be shown that it is not easy to combine the different statistics for each $k=1,2, \ldots, K$ into one statistic for the joint null because the statistics are mutually correlated (Nishiyama et al., 2011). To efficiently address this issue, we include a sequential-testing method as described by Nishiyama et al. (2011). First, we test for the nonparametric Granger causality in the first moment (i.e. $k=1$ ). 
Nevertheless, failure to reject the null for $k=1$ does not automatically lead to no-causality in the second moment. Thus, we can still construct the tests for $k=2$. Jeong et al. (2012) establish that the re-scaled statistics $T h^{p} \hat{J}_{T} / \hat{\sigma}_{0}$ is asymptotically distributed as standard normal, where $\hat{\sigma}_{0}=\sqrt{2} \theta(1-\theta) \sqrt{1 /\left(T(T-1) h^{2 p}\right)} \sqrt{\sum_{t \neq s} K^{2}\left(\left(Z_{t-1}-Z_{s-1}\right) / h\right)}$. The most crucial element of the test statistics $\hat{J}_{T}$ is the regression error $\hat{\varepsilon}_{t}$. Since the regression error in under Eq. (14) is again an error in terms of the quantile, the asymptotic distribution of the test is not affected and the re-scaled statistics $T h^{p} \hat{J}_{T} / \hat{\sigma}_{0}$ is analogously asymptotically distributed as standard normal.

The empirical implementation of causality testing via quantiles entails specifying three important choices: the bandwidth $h$, the lag order $p$, and the kernel type for $K(\cdot)$ and $L(\cdot)$ respectively. Following the suggestions in Balcilar et al., (2016a), in this study, we make use of the Schwarz information Criterion (SIC) to determine the lag length, the leave-one-out least squares cross-validation techniques to choose the bandwidth value, and Gaussian-type kernels for $K(\cdot)$ and $L(\cdot)$.

An advantage of having high frequency (daily) data for Islamic stock and bond indices is that we are also able to compute a measure of realized volatility, which allows us to check the robustness of our findings, especially related to the measure of market volatility (i.e., squared returns). The measure that we consider is the classical estimator of realized volatility, i.e. the sum of squared daily returns (Andersen and Bollerslev, 1998) expressed as

$$
R V_{t}=\sum_{i=1}^{M} r_{t, i}^{2}
$$

where $r_{t, i}$ is the daily $M \times 1$ return vector and $i=1, \ldots, M$ the number of daily returns. The obtained monthly realized volatility can now be used instead of squared returns in the quantile causality, when analyzing the impact of the monthly GPR index.

Note that the test developed by Balcilar et al., (2016a) is k-th moment test of the dependent variable. So when the dependent variable is returns, the second moment captured by the squared returns is what is traditionally defined as volatility in the extant literature. In other words, with 
returns as the dependent variable, the test of volatility (squared returns) follows naturally from the framework developed by Balcilar et al., (2016a), i.e., the estimate of volatility used is modelfree. Volatility being a latent variable, there are large number of models that aim to capture behavior of volatility, which in the first place is measured by squared returns. In this regard the GARCH-family models of conditional volatility are most well-known. But an open question is, which GARCH model to use, as different models are aimed to capture different feature of squared returns. Given this uncertainty, we used realized volatility, which is a model free estimate of volatility, given the advantage of having higher frequency (daily) data on the Islamic equity and bonds. This is in some sense in line with the test, which uses squared returns to capture volatility, which in turn, follows obviously from the second moment of the dependent variable (without having to estimate a specific GARCH-type model of conditional volatility), which in our case is returns. As pointed out by Balcilar et al., (2016b), given what the k-th moment test aims to achieve, if any measure of volatility should be used besides squared returns, statistically it should be a model-free estimate, like the realized-volatility used in our case.

\section{Data and Empirical Findings}

\subsection{Data}

Monthly data on geopolitical risk (GPR) is downloaded from: https://www2.bc.edu/matteoiacoviello/gpr.htm, and is based on the work of Caldara and Iacoviello (2016). This paper constructs the GPR index by counting the occurrence of words related to geopolitical tensions, derived from automated text-searches in leading 11 national and international newspapers (The Boston Globe, Chicago Tribune, The Daily Telegraph, Financial Times, The Globe and Mail, The Guardian, Los Angeles Times, The New York Times, The Times, The Wall Street Journal, and The Washington Post). The eight phrases considered for constructing the index are: "geopolitical risk(s)", “geopolitical concern(s)", "geopolitical tension(s)", "geopolitical uncertainty(ies)", "war risk(s)" (or "risk(s) of war"), and "military threat(s)", "terrorist threat(s)", "terrorist act(s)", and "Middle East AND tensions". Then, Caladara and Iacoviello (2016) 
calculate the index by counting, in each of the above-mentioned 11 newspapers, the number of articles that contain the search terms above for every month starting in 1985 . The index is then normalized to average a value of 100 in the 2000-2009 decade. We take logarithms of this data, and find it to be stationary in log-levels based on standard unit root tests. ${ }^{2}$

Both daily and monthly data on Islamic stock (Dow Jones Islamic World) and bond (Dow Jones Sukuk) price indices are obtained from Datstream of Thomson Reuters. Returns are measured in terms of the first-difference of the natural $\log$ of the stock and bond indices. Using returns ensures that the dependent variable is stationary, just like the GPR index - a requirement for our causality analysis. ${ }^{3}$ Based on data availability, the starting periods for of the stocks and bonds vary, however the end date is always March, 2017 to correspond with the end point of the GPR index. The Islamic equity returns data starts in January, 1996 (255 observations); while, the Sukuk returns data begins in October, 2005 (138 observations). Realized volatility estimates are based on $2^{\text {nd }}$ January, 1996 to $31^{\text {st }}$ March, 2017 (5544 observations) and $3^{\text {rd }}$ October, 2005 to $31^{\text {st }}$ March, 2017 (3000 observations) daily observations for Islamic stocks and bonds date respectively. The data have been summarized in Table A1 in the Appendix of the paper. As can be seen that the Jarque-Bera test overwhelmingly rejects the null hypothesis of normality for all the variable concerned, which in turn provides us the initial motivation to use causality-inquantiles test to capture the heavy tails of the data. The non-normality is due to the negative skewness in the returns of Islamic equities and bonds, and positive skewness of their respective volatilities (squared and realized), and consistently excess kurtosis. The GPR has positive skewness and excess kurtosis causing it to be strongly non-normal as well.

\subsection{Causality tests}

Figures 1 and 2 provide the results of the causality-in-quantiles tests for market return, volatility (measured by squared returns), and realized volatility as described in Eq. (9) for Islamic stocks and bonds respectively. The estimations are performed over the quantile range of 0.05 to 0.95 . In

${ }^{2}$ Complete details of the unit root tests are available upon request from the authors.

${ }^{3}$ Details of the unit-root tests are available upon request from the authors. 
each figure, test statistics for alternative quantiles of the conditional distributions of returns and volatility measures are provided, and when the test statistic is above the 5 percent critical value of 1.96, we reject the null hypothesis of non-causality at that specific quantile. ${ }^{4}$

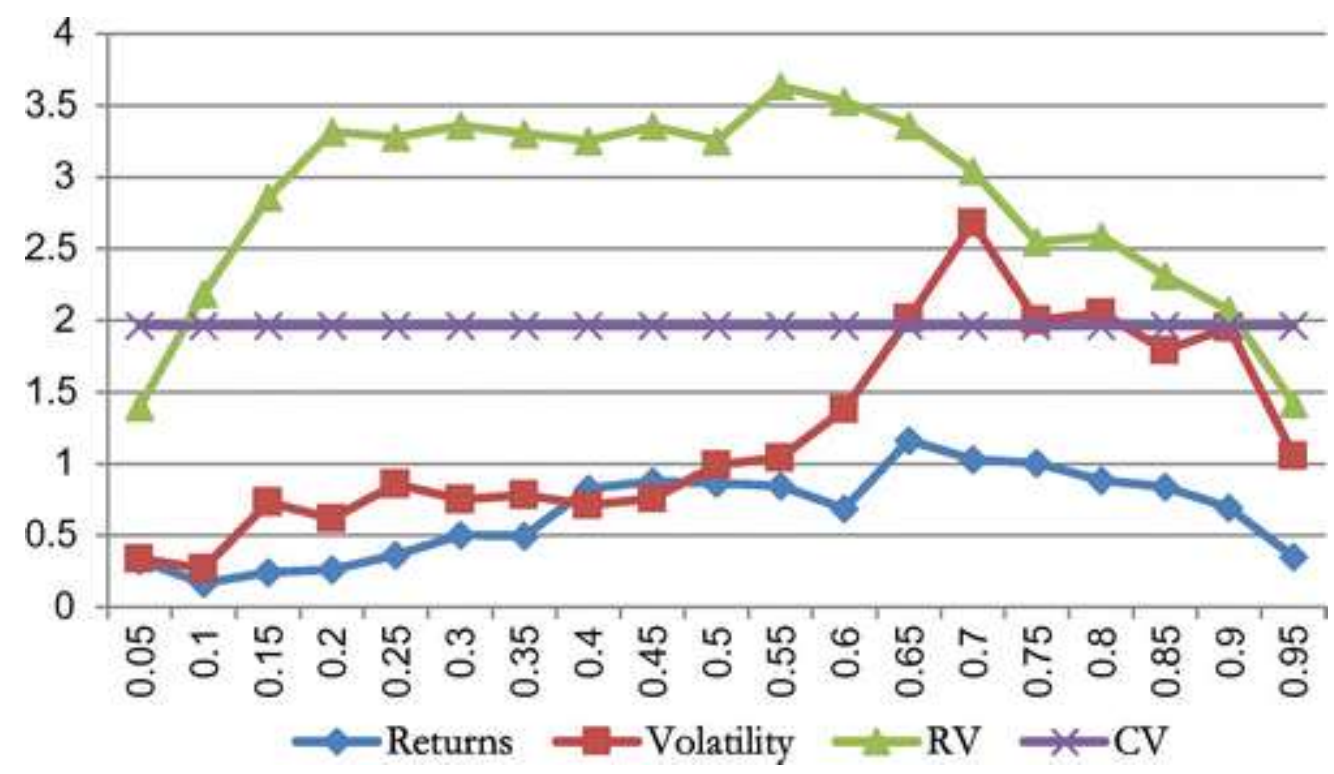

Figure 1. Causality-in-Quantiles Test for Dow Jones Islamic World Equity Index.

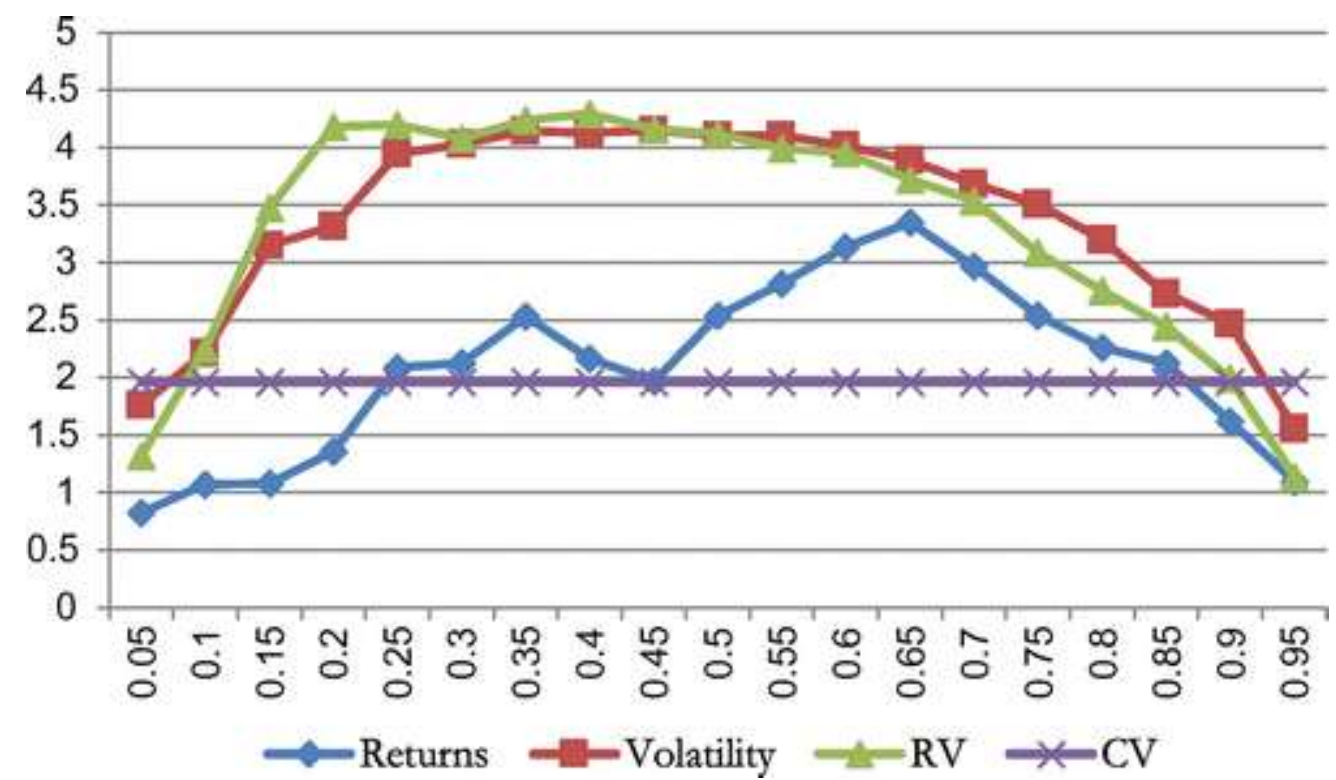

Figure 2. Causality-in-Quantiles Test for Dow Jones Sukuk Index.

\footnotetext{
${ }^{4}$ We also conducted linear Granger causality tests, but could not detect any causality running from GPR to Islamic equity and bond returns. However, with the Brock et al., (1996, BDS) test showing strong evidence of nonlinearity in the relationship between returns and GPR, the results from the misspecified linear model cannot be deemed as robust. Complete details of these results are available upon request from the authors.
} 
Examining the findings for Islamic equity returns, as captured by the Dow Jones Islamic World Equity Index, GPR is found to have no impact on returns over its entire conditional distribution. ${ }^{5}$ This finding is in line with other emerging markets where GPR is not found to have predictive ability over equity returns (Balcilar et al., forthcoming). However, when we look at return volatility measured by the squared variance of returns, GPR is found to cause volatility over the quantile range of 0.65 to 0.80 , i.e., at the moderate upper quantiles. Similarly, when we look at realized volatility, the effect of GPR is exceptionally strong, implying that GPR can predict realized volatility over the quantile range of 0.10 to .90 , i.e., barring the extreme quantiles of the conditional distribution. ${ }^{6}$ These results are similar to those reported in the literature on conventional stock markets, i.e., geopolitical risks tend to affect volatility (and especially realized volatility - a more robust measure of variance) more than returns ${ }^{7}$ (see for example, Balcilar et al., (2016b, 2017, forthcoming), and Apergis et al., (2017)). ${ }^{8}$ These findings suggest that the effect of GPRs on equity markets is largely transmitted via the volatility channel and policy makers who are concerned about the negative effects of volatility in local markets should monitor development related to GPRs and implement circuit breakers based on volatility forecasting models that include GPR based variables as predictors.

Overall, the tests on Islamic equities suggest that these securities behave similar to conventional equities in other emerging nations with regard to their causal links to geopolitical risks. The finding that the GPR effect is observed only on the volatility of returns suggests that

\footnotetext{
${ }^{5}$ So, even with the correctly specified model, as with the linear Granger causality test (discussed in Footnote 4), we are unable to detect any predictability emanating from GPR to returns.

${ }^{6}$ We also computed so-called good and bad volatilities, based on the realized volatilities obtained from (only) positive returns and negative returns respectively. Our results were qualitatively similar, and are available upon request from the authors.

7 Besides the benchmark GPR index, Caldara and Iacoviello (2016) also provides two sub-indices namely, GPR associated with threats and GPR associated with actual Acts. We obtained qualitatively similar results when using these sub-indices, complete details of which are available upon request from the authors

${ }^{8}$ In fact, we confirmed these results when using the MSCI world equity index, i.e., GPR predicts volatility but not returns of the conventional equity market. Complete details of these results are available upon request from the authors.
} 
equity markets are affected by common global economic uncertainties, driving return volatility in these markets regardless of their classification and conventional or Sharia-compliant.

Examining the impact of GPRs on Islamic bonds, however, present a different story on how GPRs relate to financial returns (Figure 2). Unlike the case for Islamic equities, we observe that GPRs can predict bond returns over the quantile range of 0.25 to 0.85 , i.e., barring the extreme quantiles. ' This implies that geopolitical risks possess predictive ability over Islamic bond returns during most market states with the exception of extreme market conditions. This finding implies that the excess returns offered by Islamic bonds over their conventional counterparts, as documented in the literature, could in part be driven by the compensation investors have required for their exposure to GPRs. From an asset pricing perspective, one can argue that GPRs serve as a systematic risk factor driving returns in the market for Islamic bonds and valuation models for these assets must include GPR based factors in their pricing models in order to correctly price these assets. These findings also present a challenge to the argument that these assets can serve as safe havens during turbulent times as our findings imply that GPR exposure can potentially nullify any return benefits these assets might offer, even during normal market states.

However, as in the case of the equities, strong evidence of predictability from GPR is found for both squared returns and realized volatility over the quantile range of 0.10 to 0.90 . In other words, GPR can predict both return and volatility in the Islamic bond market barring the extreme ends of the conditional distributions of returns and volatilities, i.e., except when the market is in extreme bear and bull phases..$^{10,11}$

\footnotetext{
9 This result highlights the importance of using a nonparametric causality-in-quantiles approach over a misspecified linear Granger causality test, which as discussed in Footnote 4, could not detect causality running from GPR to bond returns.

10 The results for returns and volatilities continued to hold qualitatively under the sub-indices of threats and acts, and also when we analysed good and bad volatilities. Complete details of these results are available upon request from the authors.
} 
This finding, coupled with strong results observed for returns, presents a double challenge to the diversification benefits that these asset might offer, particularly during normal market periods. From a policy-making perspective, any forecasting model must include measures of geopolitical risks in order to assess the potential negative effects on price and reinvestment risks experienced by bond investors. To that end, it would be particularly interesting to examine if the same relationship holds in the case of sovereign bond yields as well as it can provide insight to whether GPRs have a direct effect on the credit risk of sovereigns. On the other hand, the finding of an insignificant GPR effect at extreme quantiles is in a way supportive of the recent arguments by Hkiri et al. (2017) that Islamic assets can serve as a safe haven during financial crisis periods characterized by extreme market conditions. To that end, the finding that GPRs do not have a significant effect on return dynamics during such periods, suggests that Islamic restrictions based on religious criteria present the greatest benefits during such markets states when those risk reduction benefits are not nullified by the negative effects exerted by GPRs.

Unlike, the conventional equity markets, there is very little work on the impact of geopolitical risks on returns and volatilities of conventional bond markets, though there does exist some work on the impact of terror attacks on the comovements of stocks and bonds (see for example, Kollias et al., (2013a); Gupta et al., (2017)). The two studies that we could find were that of Hempel (2016) and Schepers (2016), which tend to indicate the impact of terror attacks

\footnotetext{
11 Based on the suggestions of an anonymous referee we conducted our analyses of causality-in-variance by obtaining measures of conditional volatility from a GARCH(1,1) model (as suggested by Ben Nasr (2016)). The GARCH(1,1) models are estimated using monthly data, as well as, daily data. In the latter case, we recover the GARCH-fitted variance from the daily data and sum it over a month to obtain a comparable model-based measure of realized volatility to our model-free estimate of the same. When monthly data-based GARCH models were used, there was no evidence of predictability for the Islamic equity over any part of its conditional distribution, while for Sukuk causal effect was observed only at the quantile of 0.40 . When we used the GARCH-based estimate of realized volatility, again there was no causal impact on the volatility of the Islamic finance equities, but impact on Sukuk was observed over the entire conditional distribution barring the extreme quantiles of 0.05 and 0.95 . Complete details of these results are available upon request from the authors. These findings highlight the sensitivity of the results based on how volatility is computed using the same model but across different frequencies, which in turn, makes our case stronger for the usage of model-free estimates of volatility.
} 
on conventional bond returns. Hence, our results corroborate these findings in terms of bond returns. ${ }^{12}$

In sum, our findings generally suggest that when causality exists, it tends to hold except at the extreme quantiles of the distribution. This, in turn, could be an artifact of investors' tendency to herd during extreme bear and bull market states, underscoring the effect of lagged returns in our tests, thus rendering any additional information that could be available in the movements of the GPR index insignificant. Particularly interesting, however, is observing a difference in the impact of GPR on Islamic stocks and bonds. The geopolitical events affect both returns and volatility of bond markets, but the impact on the equity markets is restricted to only volatility. ${ }^{13}$ One possible reason may be due to the fact that the issuance of Islamic bonds is primarily driven by sovereigns and governments, particularly in the Gulf Arab countries. Therefore, it can be argued that the effect of GPR on both return and risk for Islamic bonds is an artifact of the GPR effect on the country's political situation and finances. To that end, the impact of GPR on both risk and return may be related to the credit risk of the issuer. On the other hand, Islamic equity issuers are more diverse and thus, Islamic equities behave similar to conventional equities in other emerging markets as their volatilities are driven by the same common factor that affects all emerging market volatilities.

\footnotetext{
${ }^{12}$ Using the PIMCO investment grade world bond index, our quantile causality-test however showed no impact of GPR on returns, but only on volatilities - a result similar to that of the conventional equity markets. Complete details of these results are available upon request from the authors. Note that since, the works by Hempel (2016) and Schepers (2016) used conditional mean-based linear models, the obtained results from their studies could well be suffering from misspecification due to nonlinearity, and cannot be completely relied upon, even though they might be using different country-specific bond indices. As part of future research, it would be interesting to extend our current study to conventional bond markets in more detail.

13 To ensure that the difference in results is not due to the sample period, we re-conducted the analysis for the Islamic equities over 2005:10 to 2017:03, i.e., the same sample period as that of the Islamic bonds. However, the results obtained for this shorter sample continued to be the same as that of the full-sample, i.e., GPR predicted squared returns and realized volatility (except at the extreme quantiles), but not returns. Complete details of these results are available upon request from the authors.
} 


\section{Conclusion}

In the wake of the recent financial crisis, there has been a need felt for exploring alternative financial practices, and in this regard Islamic finance, believed to reduce investment risks by design, has gained prominence. In the process, a voluminous amount of work has been devoted to analyzing factors that drive Islamic instruments, just like in the case of conventional financial markets. One factor that seems to have played an important role in driving movements in conventional financial markets, amongst others, has been geopolitical risks. While there are numerous studies on the impact of such risks on conventional markets, there is virtually nothing when it comes to Islamic equity and bond markets. Against this backdrop, in this paper, we examine the effect of geopolitical uncertainty on return and volatility dynamics of Islamic equities and bonds via a nonparametric causality-in-quantiles test. We find that geopolitical risks impact return volatility in Islamic equities, rather than returns, in line with the findings for other emerging, conventional stock markets. However, we find that geopolitical risks can predict both returns and volatility measures for Islamic bonds, while causality is found to hold over the entire conditional distributions of returns and/or volatilities, barring the extreme ends of the same. We argue that the strong results observed for Islamic bonds is due to the fact that the issuance of Islamic bonds is driven by sovereigns and governments, particularly in the Gulf Arab countries, reflecting geopolitical effects on the sovereign's political situation and finances and possibly relating GPR to the credit risk of the issuers of Islamic bonds. Overall, our results imply that Islamic financial instruments are affected by geopolitical risks just as the conventional markets, and hence, cannot be used to diversify away the uncertainties associated with geopolitical events. A corollary of this result is that Islamic equity and bond markets are weakly inefficient in relation to geopolitical events. 


\section{References}

Abu-Alkheil, A., Khan, W. A., Parikh, B., Mohanty, S. K. 2017. Dynamic co-integration and portfolio diversification of Islamic andconventional indices: Global evidence. The Quarterly Review of Economics and Finance 66, 212-224

Ajmi, A.N., Hammoudeh, S., Nguyen, D., and Sarafrazi, S. 2014. How strong are the causal relationships between Islamic stock markets and conventional financial systems? Evidence from linear and nonlinear tests. Journal of International Financial Markets, Institutions and Money, 28(C), 213-227.

Álvarez Díaz, M., Hammoudeh, S., and Gupta, R. 2014. Detecting Predictable Non-linear Dynamics in Dow Jones Industrial Average and Dow Jones Islamic Market Indices using Nonparametric Regressions. North American Journal of Economics and Finance, 29(1), 22-35.

Andersen T.G., and Bollerslev T. 1998. Answering the Skeptics: Yes, Standard Volatility Models Do Provide Accurate Forecasts. International Economic Review, 39 (4), 885-905.

Apergis, N., Bonato, M., Gupta, R., and Kyei, C. 2017. Does Geopolitical Risks Predict Stock Returns and Volatility of Leading Defense Companies? Evidence from a Nonparametric Approach. Defence and Peace Economics, DOI: http://dx.doi.org/10.1080/10242694.2017.1292097.

Arshad, S., \& Rizvi, S. A. R. (2013). The impact of global financial shocks to Islamic indices: speculative influence or fundamental changes?. Journal of Islamic Finance, 2(1), 1-11.

Askari, H., 2012. Islamic finance, risk sharing and international financial stability. Yale Journal of International Affairs 7, 1-8.

Aslam, F., \& Kang, H. G. (2015). How different terrorist attacks affect stock markets. Defence and Peace Economics, 26(6), 634-648.

Bahloul, S., Mroua, M., and Naifar, N. 2017. The impact of macroeconomic and conventional stock market variables on Islamic index returns under regime switching. Borsa Istanbul Review, 17(1), 62-74.

Balcilar, M., Demirer, R. and Hammoudeh, S. 2015. Global Risk Exposures and Industry Diversification with Sharia-compliant Equity Sectors, Pacific-Basin Finance Journal 35 (November), 499-520.

Balcilar, M., Bekiros, S., and Gupta, R. 2016a. The role of news-based uncertainty indices in predicting oil markets: a hybrid nonparametric quantile causality method. Empirical Economics, DOI: 10.1007/s00181-016-1150-0.

Balcilar, M., Bonato, M., Demirer, R., and Gupta, R. Forthcoming. Geopolitical Risks and Stock Market Dynamics of the BRICS. Economic Systems.

Balcilar, M., Gupta, R., Pierdzioch, C., and Wohar, M.E. 2016b. Terror Attacks and StockMarket Fluctuations: Evidence Based on a Nonparametric Causality-in-Quantiles Test for the 
G7 Countries. European Journal of Finance, DOI: http://dx.doi.org/10.1080/1351847X.2016.1239586.

Balcilar, M., G. Cerci, and R. Demirer 2016c. Is there a role for Islamic bonds in global diversification strategies?, Managerial Finance 42 (7), 656-679.

Balcilar, M., Gupta, R., Pierdzioch, C., and Wohar, M.E. 2017. Do Terror Attacks Affect the Dollar-Pound Exchange Rate? A Nonparametric Causality-in-Quantiles Analysis. North American Journal of Economics and Finance, 41(1), 44-56.

Bandyopadhyay, S., Sandler, T., \& Younas, J. (2013). Foreign direct investment, aid, and terrorism. Oxford Economic Papers, 66(1), 25-50.

Beck, T., Demirguc-Kunt, A., Merrouche, O., 2013. Islamic vs. conventional banking: business model, efficiency and stability. J. Bank. Financ. 37, 433-447.

Ben Nasr, A., Lux, T., Ajmi, A.N., and Gupta, R. 2016. Forecasting the Volatility of the Dow Jones Islamic Stock Market Index: Long Memory vs. Regime Switching. International Review of Economics and Finance, 45(1), 559-571.

Bouri, E. (2014). Israeli-Hezbollah war and global financial crisis in the Middle East and North African equity markets. Journal of Economic Integration, 1-19.

Brock, W., Dechert, D., Scheinkman, J., and LeBaron, B. 1996. A test for independence based on the correlation dimension. Econometric Reviews, 15 197-235.

Caldara, D., and Iacoviello, M. 2016. Measuring Geopolitical Risk. Working Paper, Board of Governors of the Federal Reserve Board.

Charles, A., \& Darné, O. (2006). Large shocks and the September 11th terrorist attacks on international stock markets. Economic Modelling, (23), 683-698.

Chen, A., \& Siems, T. (2004). The effects of terrorism on global capital markets. European Journal of Political Economy, 20, 349-366.

Dewandaru, G., Masih, R., Bacha, O. I., \& Masih, A. M. M. (2017). The role of Islamic asset classes in the diversified portfolios: Mean variance spanning test. Emerging Markets Review, 30, 66-95.

Drakos, K. (2010). Terrorism activity, investor sentiment, and stock returns. Review of Financial Economics, 19, 128-135.

Greenbaum, Robert, Laura Dugan and Gary LaFree. 2007. The Impact of Terrorism on Italian Employment and Business Activity. Urban Studies 44:1093-1108.

Gupta, R., Hammoudeh, S., Simo-Kengne, B., and Sarfarzi, S. 2014. Can the Sharia-Based Islamic Stock Market Returns be Forecasted Using Large Number of Predictors and Models? Applied Financial Economics, 24(17), 1147-1157. 
Gupta, R., Majumdar, A., Pierdzioch, C., and Wohar, M.E. 2017. Do Terror Attacks Predict Gold Returns? Evidence from a Quantile-Predictive-Regression Approach. Quarterly Review of Economics and Finance, DOI: https://doi.org/10.1016/j.qref.2017.01.005.

Guyot, A. 2011. Efficiency and Dynamics of Islamic Investment: Evidence of Geopolitical Effects on Dow Jones Islamic Market Indexes. Emerging Markets Finance and Trade, 47(6), 24-45.

Hasan, M., Dridi, J., 2010. The Effects of the Global Crisis on Islamic and Conventional Banks: A Comparative Study, IMF Working Paper No., WP/10/201, September.

Hempel, S.J. 2016. How do Stock Markets and Bond Markets in a Country Behave in Response to Terrorist Attacks? Masters of Arts Thesis, University of Georgia. Downloadable from: https://getd.libs.uga.edu/pdfs/hempel samuel_j 201605 ma.pdf.

Herwany, A., \& Febrian, E. (2013). Portfolio Volatility of Islamic and Conventional Stock: The Case of Indonesia Stock Market. http://dx.doi.org/10.2139/ssrn.2331803.

Hkiri, B., Hammoudeh, S., Aloui, C., Yarovaya, L. 2017. Are Islamic indexes a safe haven for investors? An analysis of total, directional and net volatility spillovers between conventional and Islamic indexes and importance of crisis periods

Ho, C. S. F., Rahman, N. A. A., Yusuf, N. H. M. and Zamzamin, Z. 2014. Performance of global Islamic versus conventional share indices: International evidence. Pacific-Basin Finance Journal 28:110-21.

Hussein, K., and Omran. M. 2005. Ethical Investment Revisited: Evidence from Dow Jones Islamic Indexes. Journal of Investing, 12(2,(Fall)), 105-124.

Jeong, K., Härdle, W. K. and Song, S., 2012. A consistent nonparametric test for causality in quantile. Econometric Theory 28, 861-887.

Kollias, C., Kyrtsou, C., and Papadamou, S. 2013b. The Effects of Terrorism and War on the Oil and Prices - Stock Indices Relationship. Energy Economics, 40, 743-752.

Kollias, C., Papadamou, S., and Arvanitis, V. 2013a. Does terrorism affect the stockbond covariance? Evidence from European countries. Southern Economic Journal, 79 (4), 832-548.

Kollias, C., Papadamou, S., and Stagiannis, A. 2010. Armed conflicts and capital markets: the case of the Israeli military offensive in the Gaza Strip. Defence and Peace Economics, 21 (4), 357-365.

Kollias, C., Papadamou, S., and Stagiannis, A. 2011a. Terrorism and capital markets: the effects of the Madrid and London bomb attacks. International Review of Economics and Finance, 20 (4), 532-541.

Kollias, C., Papadamou, S., and Stagiannis, A. 2011b. Stock markets and terrorist attacks: comparative evidence from a large and a small capitalization market. European Journal of Political Economy, 27 (S1), S64-77.

Nazlioglu, S., Hammoudeh, S., and Gupta, R. 2015. Volatility Transmission between Islamic and Conventional Equity Markets: Evidence from Causality-in-Variance Test. Applied Economics, 47(46), 4996-5011. 
Naifar, N. 2016. Do global risk factors and macroeconomic conditions affect global Islamic index dynamics? A quantile regression approach. The Quarterly Review of Economics and Finance, 61(C), 29-39.

Naifar, N., and Hammoudeh, S. 2016. Do global financial distress and uncertainties impact GCC and global sukuk return dynamics? Pacific-Basin Finance Journal, 39(C), 57-69.

Naifar, N., Mroua, M., and Bahloul, S. 2017. Do regional and global uncertainty factors affect differently the conventional bonds and sukuk? New evidence. Pacific-Basin Finance Journal, 41(1), 65-74.

Naifar, N., Mseddi, S. 2013. Sukuk spreads determinants and pricing model methodology. AfroAsian Journal of Finance and Accounting, 3(3), 241-257.

Nishiyama, Y., Hitomi, K., Kawasaki, Y., and Jeong, K. 2011. A consistent nonparametric Test for nonlinear causality - specification in time series regression. Journal of Econometrics 165, 112-127.

Muteba Mwamba, J.W., Hammoudeh, S., and Gupta, R. 2017. Financial Tail Risks and the Shapes of the Extreme Value Distribution: A Comparison between Conventional and ShariaCompliant Stock Indexes. Pacific-Basin Finance Journal, 42(1), 60-82.

Rapach, D., and G. Zhou. 2013. Forecasting Stock Returns: in Handbook of Economic Forecasting, Volume 2A, Graham Elliott and Allan Timmermann (Eds.) Amsterdam: Elsevier, $328-383$.

Reboredo, J.C., and Naifar, N. 2016. Do Islamic Bond (Sukuk) Prices Reflect Financial and Policy Uncertainty? A Quantile Regression Approach. Emerging Markets Finance and Trade, http://dx.doi.org/10.1080/1540496X.2016.1256197.

Schepers, M. 2016. Effect of terror attacks on the bond and stock market of European countries. Master Thesis, Nijmegen School of Management, Radboud University. Downloadable from: http://theses.ubn.ru.nl/bitstream/handle/123456789/2791/16.069\%20MTHEC_RU_Martijn _Schepers_s4114477.pdf?sequence $=1$.

Trabelsi, N., \& Naifar, N. (2017). Are Islamic stock indexes exposed to systemic risk? Multivariate GARCH estimation of CoVaR. Research in International Business and Finance, $42,727-744$. 


\section{Appendix:}

Table A1: Summary Statistics:

\begin{tabular}{|c|c|c|c|c|c|c|c|}
\hline & \multicolumn{7}{|c|}{ Variable } \\
\hline Statistic & DJIF_Returns & $\begin{array}{c}\text { DJIF_Squared } \\
\text { Returns }\end{array}$ & DJIF_RV & SUKUK_Returns & $\begin{array}{c}\text { SUKUK_Squared } \\
\text { Returns }\end{array}$ & SUKUK_RV & LGPR \\
\hline Mean & 0.0051 & 0.0017 & 0.0022 & 0.0002 & 0.0004 & 0.0004 & 4.3951 \\
\hline Median & 0.0111 & 0.0006 & 0.0013 & 0.0006 & 0.0000 & 0.0000 & 4.3552 \\
\hline Maximum & 0.1051 & 0.0660 & 0.0463 & 0.0799 & 0.0211 & 0.0246 & 5.9741 \\
\hline Minimum & -0.2569 & 0.0000 & 0.0001 & -0.1453 & 0.0000 & 0.0000 & 3.5213 \\
\hline Std. Dev. & 0.0405 & 0.0046 & 0.0037 & 0.0199 & 0.0020 & 0.0022 & 0.4580 \\
\hline Skewness & -1.4245 & 11.1399 & 7.8317 & -2.5912 & 8.3412 & 9.4471 & 0.5991 \\
\hline Kurtosis & 9.4945 & 153.0394 & 85.9228 & 27.4190 & 81.1808 & 100.5299 & 3.3469 \\
\hline Jarque-Bera & 534.3841 & 244462.4000 & 75666.3500 & 3583.0810 & 36745.6400 & 56747.1900 & 16.5352 \\
\hline Probability & 0.0000 & 0.0000 & 0.0000 & 0.0000 & 0.0000 & 0.0000 & 0.0003 \\
\hline Observations & $\begin{array}{c}255 \text { (1996:01- } \\
2017: 03) \\
\end{array}$ & $\begin{array}{c}255 \text { (1996:01- } \\
2017: 03) \\
\end{array}$ & $\begin{array}{c}255 \\
(1996: 01- \\
2017: 03) \\
\end{array}$ & $\begin{array}{c}138(2005: 10- \\
2017: 03) \\
\end{array}$ & 138 (2005:10-2017:03) & $\begin{array}{c}138(2005: 10- \\
2017: 03)\end{array}$ & $\begin{array}{c}255 \\
(1996: 01- \\
2017: 03) \\
\end{array}$ \\
\hline
\end{tabular}

Note: DJIF stands for Dow Jones Islamic World, and SUKUK stands for Dow Jones Sukuk; RV is realized volatility based on squared returns of daily data; LGPR is the natural

log of geopolitical risks index; Std. Dev. is standard deviation; Probability corresponds to the null of the Jarque-Bera test of normality. 